УДК 007.51

Р. І. Дзінько, О. І. Лісовиченко

\title{
ІНФОРМАЦЙНИЙ МЕТОД РЕЗЕРВУВАННЯ СИСТЕМИ ОПЕРАТИВНОГО УПРАВЛІННЯ ГНУЧКИХ ВИРОБНИЧИХ СИСТЕМ НА БАЗІ ПРИХОВАНИХ МАРКІВСЬКИХ МОДЕЛЕЙ
}

Анотація: розроблена програмна реалізація інформаційного методу резервування системи оперативного управління гнучкої виробничої системи, що базується на прихованій марківській моделі виробничого процесу. Проведені експериментальні дослідження розробки на декількох моделях виробничих систем різного компонування з різних ланцюжками технологічних та транспортних операцій.

Ключові слова: система оперативного управління, приховані марківські моделі, інформаційне резервування, алгоритм, дискретно-подійне моделювання.

\section{Вступ}

На сьогодні немає розробленого методу резервування компонентів системи оперативного управління (СОУ) гнучких виробничих систем, що дозволяв би підтримувати систему оперативного управління в працездатному стані, у випадку, коли виникають повні відмови обладнання інформаційновимірювальної системи (IBC) СОУ ГВС, а технологічне виробниче обладнання при цьому залишається працездатним [2]. Попередні дослідження показали, що вирішити дану проблему можна з застосуванням математичного апарату прихованих марківських моделей $[1,2]$.

Дана стаття описує інфомаційний метод резервування інформаційно-вимірювальної системи на базі апарату прихованих марківських моделей шляхом інтеграції в структуру СОУ з синхронною моделлю нового компонента $[1,3]$.

\section{Постановка задачі}

В процесі виконаня попередніх досліджень інформаційних методів резервування системи оперативного управління (СОУ) гнучкої виробничої системи (ГВС), була виконана побудова прихованої марківської моделі ходу виробничого процесу $[1,2]$, що дозволяє здійснити постановку наступних задач, ціллю який є, власне, створення способу резервування:

- розробити інформаційний метод резервування шляхом створення імітаційної моделі виробництва на базі апарату прихованих марківських

\footnotetext{
${ }^{\odot}$ Р. І. Дзінько, О. І. Лісовиченко
} 
моделей з можливістю застосування в процесі здійснення керування технологічними процесами;

- розробити імітаційну модель та її програмну реалізацію для проведення експериментальних досліджень, а також підтвердження ефективності отриманих теоретичних результатів.

\section{Відновлення інформації про хід виробничого процесу}

Нехай задана модель ходу виробничого процесу ГВС у вигляді прихованої марківської моделі в загальному вигляді: $\lambda=(S, \Omega, \pi, A, B)$ де $s$ - множина станів системи, що фіксується інформаційно-вимірювальною системою (IBC), $\Omega$ - множина видимих подій, $\pi$ - початковий вектор станів системи, $A$ - матриця переходів між станами, що будується на базі показників надійності обладнання, $B$ - матриця ймовірності спостережнь $[1,2,4]$.

Поданий метод відновлення інформації про хід виробничого процесу реалізується у вигляді комп’ютерної моделі, яку подаємо у вигляді алгоритму, представленого подною нижче блок-схемою (рис. 1).

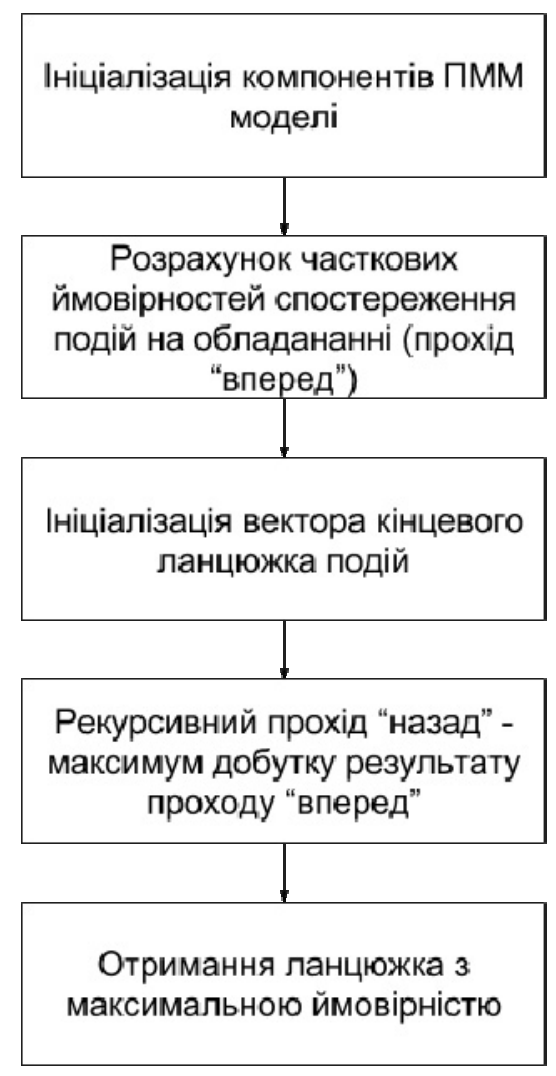

Рис. 1. Блок-схема алгоритму відновлення інформації про ланцюжок виробничих операцій 
Для оцінки працездатності та ефективності розробленої моделі були виконані експериментальні дослідження, що проводились згідно з наступним планом:

1. Обрання компонувальної схеми гнучкої виробничої лінії, наявності модуля контролю якості вихідної продукції, та періоду проведення експерименту $\left(T_{e}\right)$.

2. Задання ланцюжка технологічних операцій по випуску одиниці готової продукції.

3. Задання показників роботи та надійності виробничого обладнання, необхідних для проведення експериментів, та розрахунку інтегральних показників надійності системи. Дані показники оформлюються у вигляді таблиці (табл. 1):

а. Середнє напрацювання між відмовами () та його закон розподілу ().

b. Закон розподілу часу, необхідного для ремонту обладнання при виході його з ладу $\left(P\left(t_{D}\right)\right)$.

с.Час виконання детале-операції на кожному ГВМ чи виконання транспортування АТM $\left(T_{\downarrow} o\right)$.

d. Наявність модуля контролю якості роботи безпосередньо ГВМ.

е. Класичні способи резервування обладнання.

таблиця 1

\section{Структура таблиці показників роботи та надійності} виробничого обладнання

\begin{tabular}{|c|c|c|c|c|c|c|}
\hline 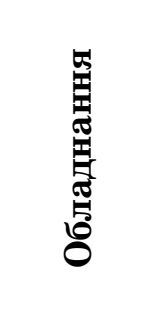 & 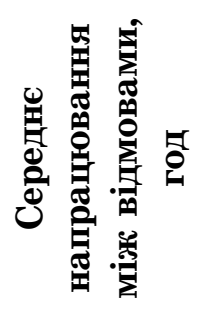 & 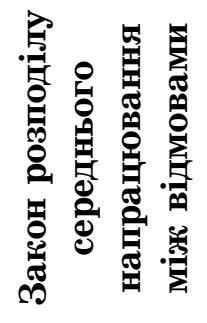 & 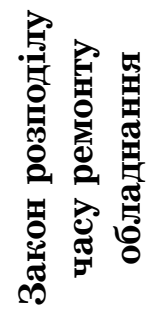 & 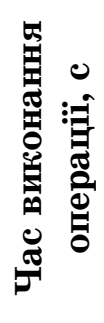 & 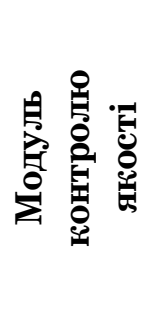 & 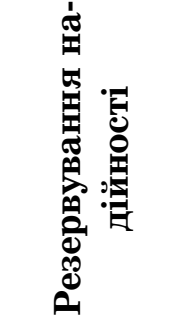 \\
\hline ГВМ-1 & $T_{\mathrm{cp} 1}$ & & $P_{1}\left(t_{D}\right)$ & $T_{o 1}$ & + & Метод-1 \\
\hline ГВМ-2 & $T_{\mathrm{cp} 2}$ & & $P_{2}\left(t_{D}\right)$ & $T_{o 2}$ & - & $\ldots$ \\
\hline$\cdots$ & $\ldots$ & $\ldots$ & $\cdots$ & ... & $\cdots$ & .. \\
\hline$\Gamma \mathrm{BM}-i$ & & & $P_{i}\left(t_{D}\right)$ & $T_{i}$ & ... & ... \\
\hline
\end{tabular}

4. Задання показників надійності компонентів IBC COУ ГВС, а також структурної композиції обладнання ВОК СОУ ГВС. Для простоти проведення кінцевих розрахунків показників надійності всієї системи, 
показники надійності компонентів вимірювальної групи задаються як один агрегований показник (табл. 2):

а. Середне напрацювання на відмову () та його закон розподілу.

b. Тип фізичного компонування вимірювальної групи (внутрішній датчик ГВМ / зовнішній, незалежний датчик).

с. Середній час, необхідний для виконання заміни та пуску нової вимірювальної групи у випадку відмови ().

d. Класичні способи резервування обладнання.

Таблиця 2

Структура таблиці показників роботи

та надійності вимірювальної групи

\begin{tabular}{|c|c|c|c|c|c|}
\hline 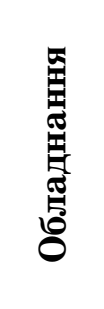 & 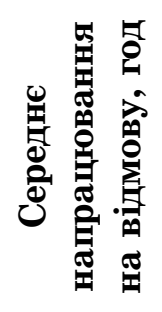 & 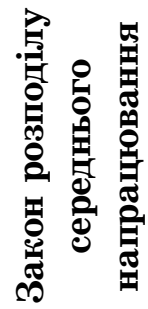 & 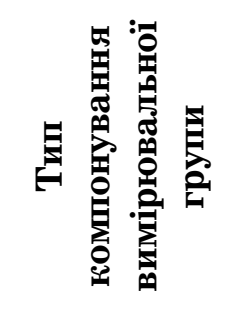 & 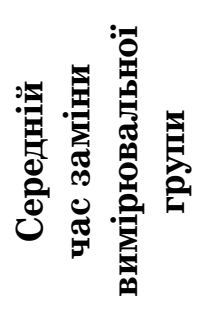 & 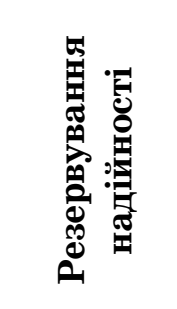 \\
\hline ВГ-1 & $T I_{\mathrm{cp} 1}$ & & внутрішній & $T Z_{\mathrm{cp} 1}$ & Метод-1 \\
\hline $\mathrm{B \Gamma}-2$ & $T I_{\mathrm{cp} 2}$ & & зовнішній & $T Z_{\mathrm{cp} 2}$ & $\ldots$ \\
\hline$\ldots$ & $\ldots$ & & $\ldots$ & $\ldots$ & .. \\
\hline $\mathrm{B} \Gamma-i$ & & & зовнішній & & $\cdots$ \\
\hline
\end{tabular}

1. Виконання імітації роботи ГВС в заданий період (пункт 1) без застосування розробленого методу інформаційного резервування на базі прихованих марківських моделей.

2. Виконання імітації роботи ГВС в заданий період (пункт 1) з застосуванням розробленого методу інформаційного резервування на базі прихованих марківських моделей.

3. Аналіз отриманих результатів ефективності застосування розробленого методу резервування на базі отриманих числових експериментальних даних, оформлених у вигляді наступних графіків та діаграм:

- графіку залежності тривалості виробничого процесу від часу за весь період роботи імітаційної моделі;

- графіку залежності кількості випущених одиниць продукції в залежності від часу за весь період роботи імітаційної моделі.

Експерименти проведемо на 2-х експериментальних компонувальних схемпах гнучкої виробничої системи (рис. 2. а, б). 


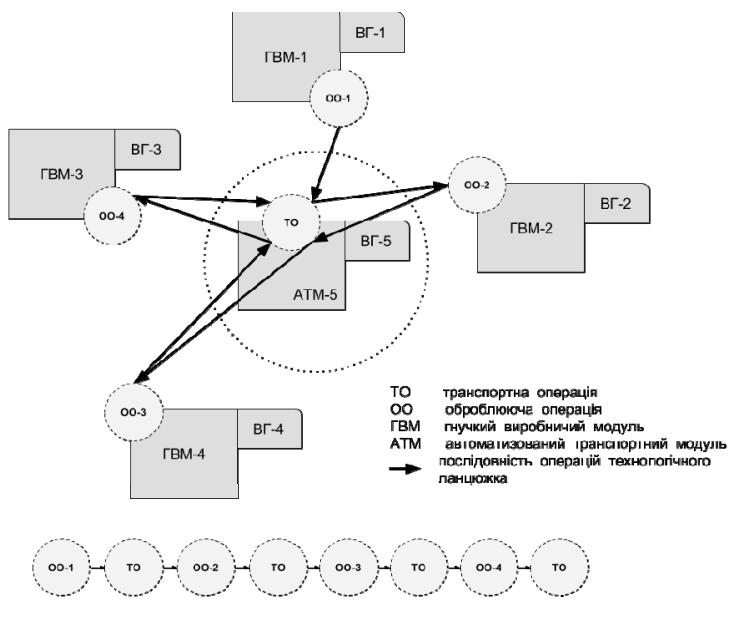

a)

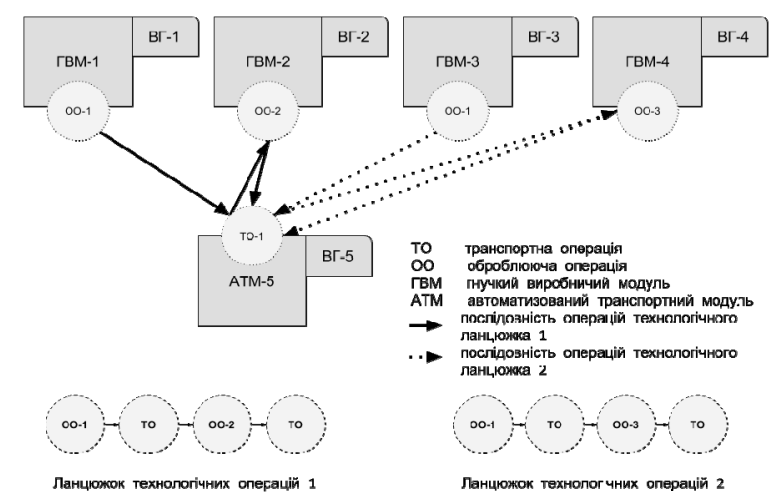

b)

Рис. 2. Компонувальні структура ГВС для експериментів

Період проведення імітаційного експерименту - 8760 годин ( 3 роки). У якості закону розподілу середнього напрацювання між відмовами обраний нормальний закон (рис. 3, a), а у якості закону розподілу часу ремонту обладнання при виникненні відмови - експоненціальний (рис. 3 , б).

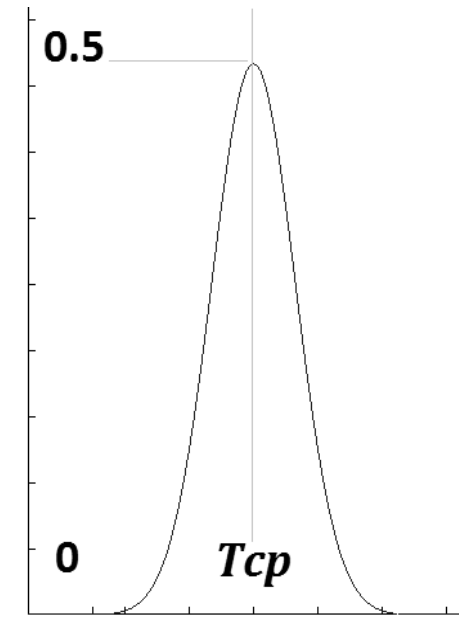

a)

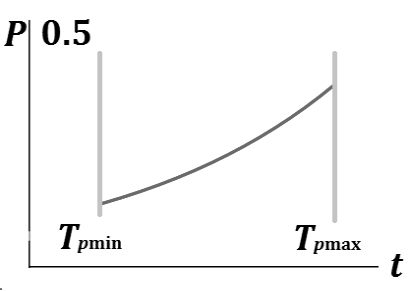

b)

Рис. 3. Закони розподілу середнього напрацювання між відмовами та середнього часу ремонту

На базі заданих характеристик роботи, а також номінальних середніх показників надійності виробничого обладнання експериментальної гнучкої виробничої системи, а також компонентів інформаційно-вимірювальної системи СОУ ГВС, виконана імітацію роботи системи, результати якої у вигляді опрацьованих експериментальних даних подані на рис. 4 (для першого експерименту) та рис. 5 (для другого експерименту). 


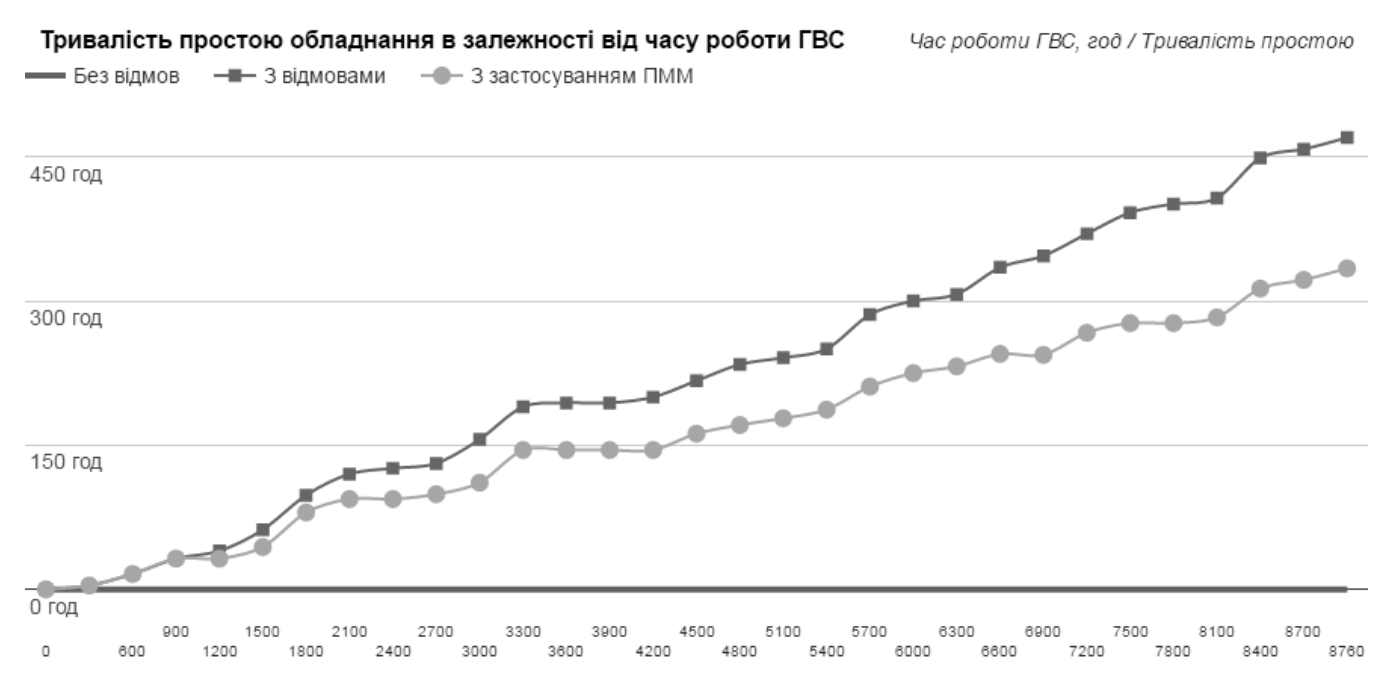

a)

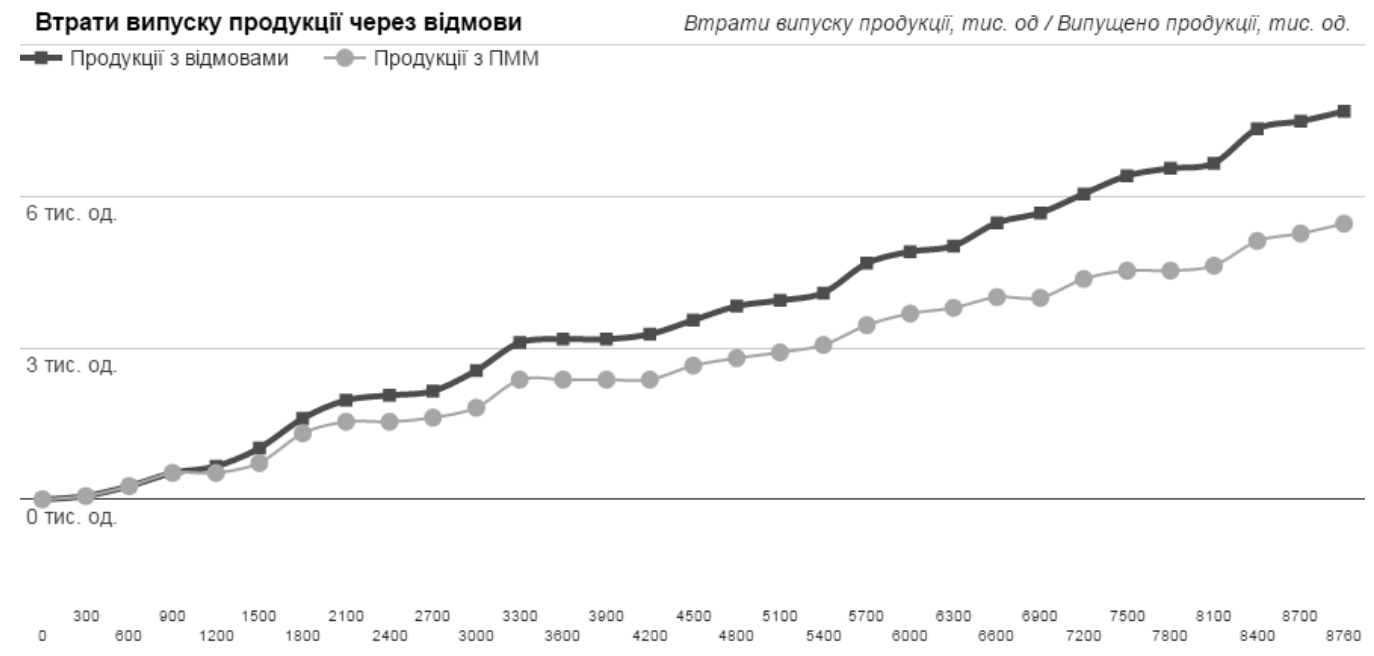

б)

Рис. 4. Результати експериментів на першій компоновці

3 проведеного експерименту бачимо (рис. 4 , а), що без застосування розробленого методу резервування тривалість простою обладнання була рівна $5,36 \%$ загального часу роботи, тоді як з використанням ПММ $3,81 \%$, тобто вдалось збільшити тривалість технологічних процесів на $1,55 \%$ при умові, що не застосовувались інші методи резервування. В процесі імітації зафіксовано 46 відмов обладнання, з них 14 разів було спрацювання ПММ, 1 з яких виявилось так званим невірним спрацюванннням алгоритму за рахунок показника різниці ймовірностей відмови ВГ та виробничого обладнання.

На базі аналізу втрат випуску продукції (рис. 5, б), бачимо, що поведінка графіку, а також процентне співвідношення величин повторює поведінку попереднього (рис 4. а), оскільки при заданих параметрах модельованої системи, а саме відсутності структурного та функціонального 
резервування, відбувається зупинка технологічного ланцюжка виробництва при виникненні відмов виробничого обладнання.

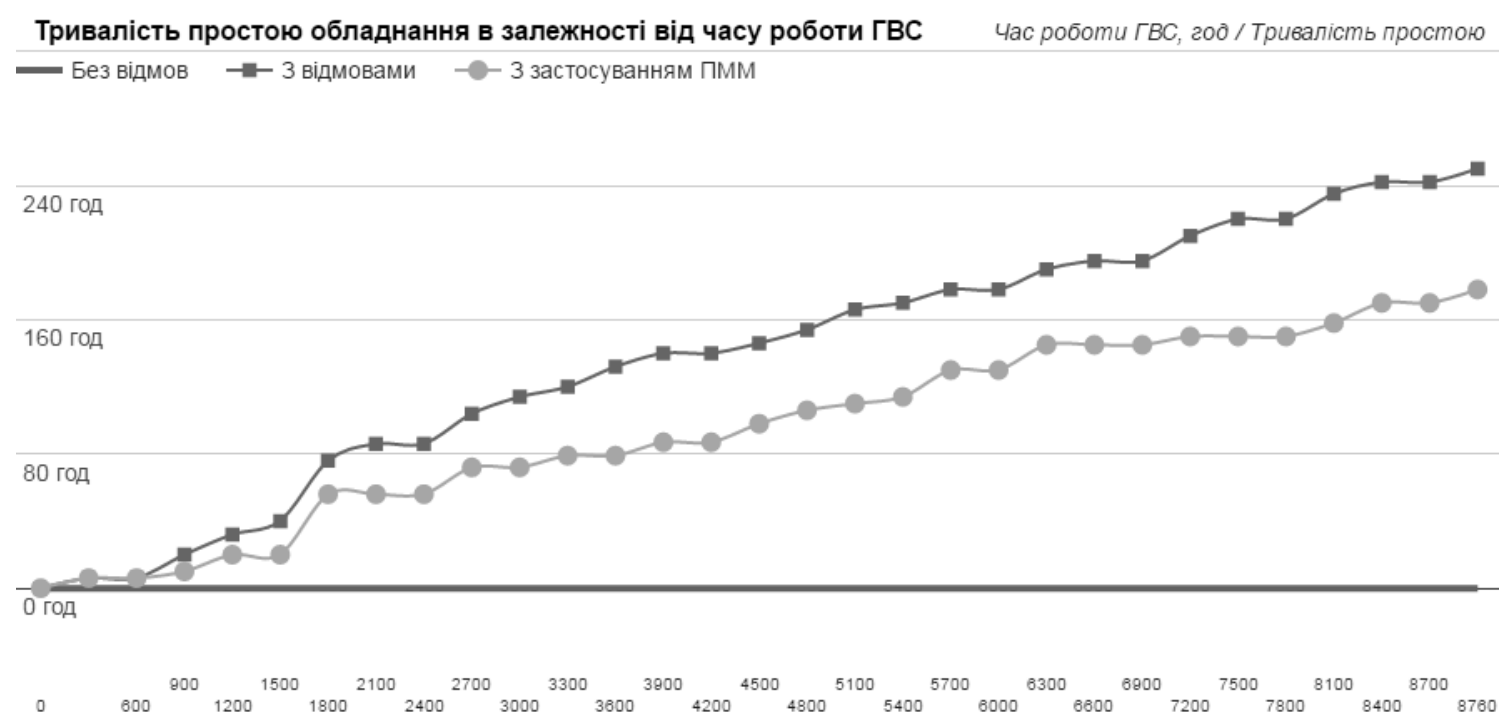

a)

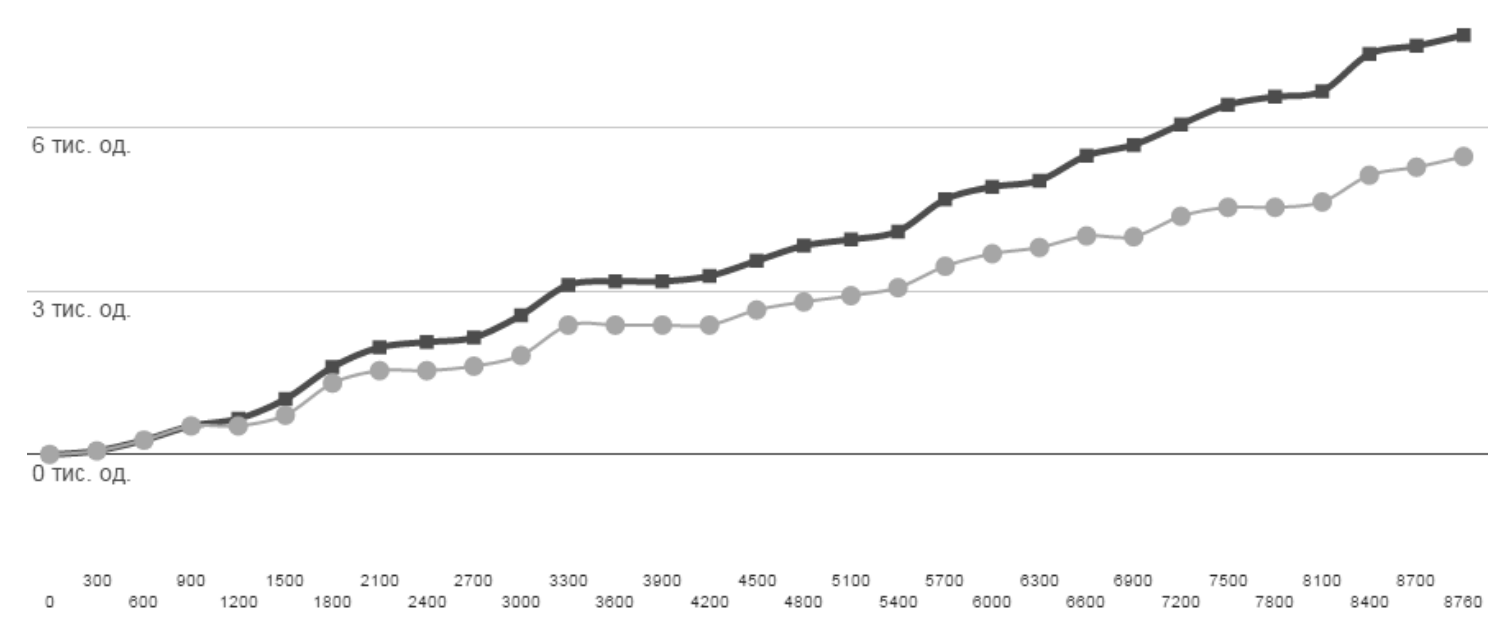

б)

Рис. 5. Результати експериментів на другій компоновці

3 проведеного експерименту бачимо (рис 5. а), що без застосування розробленого методу резервування тривалість простою обладнання була рівна $2,85 \%$ загального часу роботи, тоді як з використанням ПММ $-2,35 \%$, тобто вдалось збільшити тривалість технологічних процесів на 0,5\% при застосуванні навантаженого (70\%) резерву. В процесі імітації зафіксовано 42 відмови обладнання, з них 14 разів було спрацювання ПММ, при чому не зафіксовано невірних спрацювань алгоритму за рахунок показника різниці ймовірностей відмови ВГ та виробничого обладнання.

На базі аналізу втрат випуску продукції (рис. 5, б), бачимо, що поведінка графіку повторює поведінку попереднього (рис 5. а), проте 
кількість випущеної продукції вища за рахунок меншого застосування резервного ГВМ-3 на $0.8 \%$.

\section{Висновки}

На підставі отриманих результатів було підтверджено наступне:

- розроблений метод інформаційного резервування є працездатним та ефективним. На базі проведених імітаційних досліджень на тестових компоновках ГВС показано зростання тривалості безвідмовної роботи виробничих процесів на й з застосуванням розробленого методу на 0,5\%-1.55\% в залежності від того, чи застосовуються паралельно інші способи резервування виробничого обладнання;

- розроблений метод інформаційного резервування краще працює для меншої кількості АТМ, де присутня менша комбінація композицій потоків детале-операцій, що підтверджено більшим зростанням ймовірності безвідмовної роботи на протязі часу імітованого в рамках експерименту на другій моделі;

- при застосуванні навантажених резервів для виробничого обладнання, розроблений метод окрім підвищення показників надійності, забезпечує мінімізацію відхилення від календарного плану випуску продукції. На тестовій моделі зменшення відхилення становило 0.8\% .

\section{Список використаних джерел}

1. Дзінько Р. І. Система оперативного контролю виробництва з дублюючою синхронною моделлю / Дзінько Р. І., Лісовиченко О. І. // Адаптивні системи автоматичного управління, - 2013. - 1(22). - с. 10-16.

2. Дзінько Р.І. Підвищення відмовостійкості функціонування гнучких виробничих систем за допомогою прихованих марківських моделей / Дзінько Р. І., Лісовиченко О. I. // Адаптивні системи автоматичного управління, - №3 (24). - 2013. - с. 26-32.

3. Ямпольський Л. С. Гнучкі комп’ютеризовані системи: проектування, моделювання і управління. Комплекс з 3-х підручників / Л.С. Ямпольський, $\begin{array}{lll}\text { П. П. Мельничук, } & \text { Б. Б. Самотокін, } & \text { М. М. Поліщук, } \\ \text { M. М. Ткач, }\end{array}$ К. Б. Остапченко, О. І. Лісовиченко. - ЖЖитомир: ЖЖДТУ, 2005. - 680 с.

4. Miller David RH A hidden Markov model information retrieval system / Miller David RH, Tim Leek, Richard M. Schwartz // Proceedings of the 22nd annual international ACM SIGIR conference on Research and development in information retrieval. ACM, - 1999. - p. 241. 